\title{
The Primary Attempt of Teaching MOOC of BIM
}

\author{
Rui He \\ Department of Engineering Graphics \\ Harbin institute of technology \\ Harbin, China \\ herui@hit.edu.cn \\ Kunmao Du \\ Civil school \\ Harbin institute of technology \\ Harbin, China \\ dukunmao0528@163.com \\ Jingjing Shang \\ Architecture school \\ Harbin institute of technology \\ Harbin, China \\ 78674021@qq.com
}

\author{
Xuyang Wang * \\ Civil school \\ Harbin institute of technology \\ Harbin, China \\ 465933786@qq.com \\ *Corresponding author
}

\author{
Bisheng Bao \\ Civil school \\ Harbin institute of technology \\ Harbin, China \\ 422149991@qq.com \\ Haihan Lv \\ Architecture school \\ Harbin institute of technology \\ Harbin, China \\ 2233027030@qq.com
}

\begin{abstract}
Massive opening online course (MOOC) is wildly accepted by teachers and students these years, it brings challenge and chance to the undergraduate education. By choosing MOOC, students have more choices about teachers and study time. Teacher of Harbin institute of technology began to give BIM MOOC courses to encourage students keep learning after class . The procedure including video, question, quiz and group discussion. The result of contest and real project shows the MOOC course is useful to teaching BIM course.
\end{abstract}

Keywords-MOOC; information modling.

\section{Engineering Graphics; BIM(building}

\section{INTRODUCTION}

\section{A. $\mathrm{MOOC}$}

Since century, with the development of network, more and more online education appeared and accepted by people. Massive open online course (MOOC) is becoming a useful supplement of school education.

The first MOOC platform appeared in 2011[1], professor Sebastian of Stanford university put the "artificial intelligence" course on the network, soon attracted the attention of students. In January 2012, Sebastian established his own MOOC platform. In May 2012, Harvard University, Massachusetts institute of technology (MIT) has established the MOOC platform named edX to offer free online courses worldwide. In China, 12 universities including Peking University, Tsinghua university and Harbin institute of technology announced to create the open courses online platform, build China's first- class online courses, promote high quality teaching resources and serve the Chinese higher education and society.

Everyone's understanding of MOOC education is different, it makes MOOC education show a variety of forms.

Professor $\mathrm{Yu}$ [2] of Tsinghua university gave the MOOC course of circuit principle to the students all over the world on the internet. He put the knowledge into videos and made them interesting and short. The students fell that this teacher is giving lessons to whom watching the video. Analysis showed that, the number of students choosing his course is higher than other online courses in the same period.

Professor Li of Taiwan Hsinchu Jiao Tong univerity bring MOOC into his job. Differ with professor $\mathrm{Yu}$, professor $\mathrm{Li}$ gave MOOC to his own students. He asked his students to watch the video than every two weeks he arrange a discussion and quiz. The examination results show that the teaching effect is good. By using this method, he had save a lot of time to do his research work.

\section{B. BIM}

Building Information Modeling (BIM) [3] is an intelligent 3D model-based process for planning, design, construction, and management of buildings and infrastructure. It allows every aspect of a design's performance to be simulated and assessed before it is built; it is not simply "3D drafting" or "3D animation". There are an established set of industry definitions used to identify the different maturity levels of BIM and the concepts of $4 \mathrm{D}, 5 \mathrm{D}$ and $6 \mathrm{D}$ are used to indicate the elements and benefits of increasingly complex BIM models. 
BIM is being broadly adopted by the design team, manufacturers, and clients.

\section{MOOC OF BIM}

Since 2013, The author began to give MOOC course of BIM to the undergraduate students. More than 100 students took these courses on the internet.

In HIT, BIM course is included in Civil engineering drawing course which is offered for undergraduate students. For this kind of cut edge technology, 16 teaching hours are not enough, the author gave the MOOC course to the students who want to get a higher level of BIM.

Each week the teacher answer the questions and gave the exercises to the students, then get the feedback from the students.

The course is extra course and not in the teaching plan, so the author have not push the students to do the homework. Months later, some students could not catch up with the teacher, and some of them gave feedback on time get rapid progress.

The result of homework and quiz shows the students get progress step by step by taking MOOC course of BIM. the building 3d model set by students from April to August in 2014 are shown in figure I.

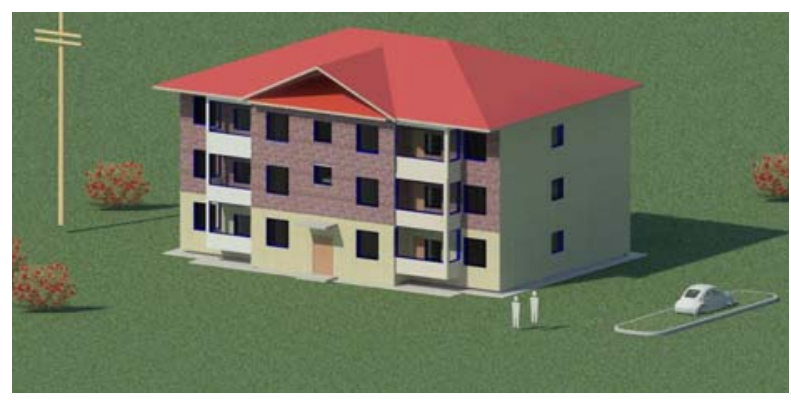

(a) 2013.12

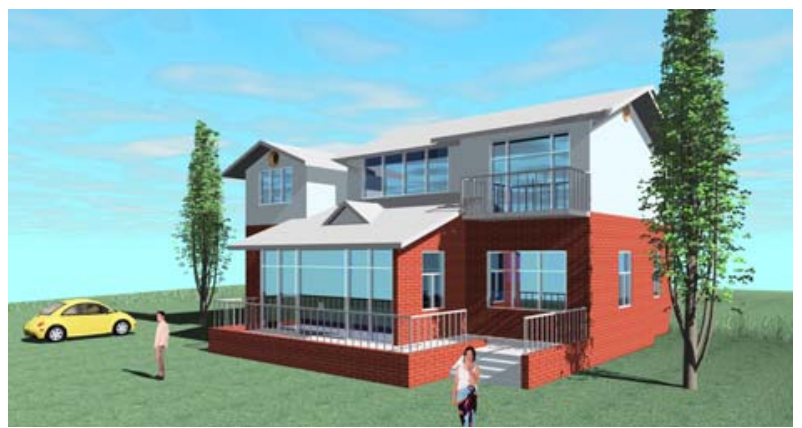

(b)2014.4

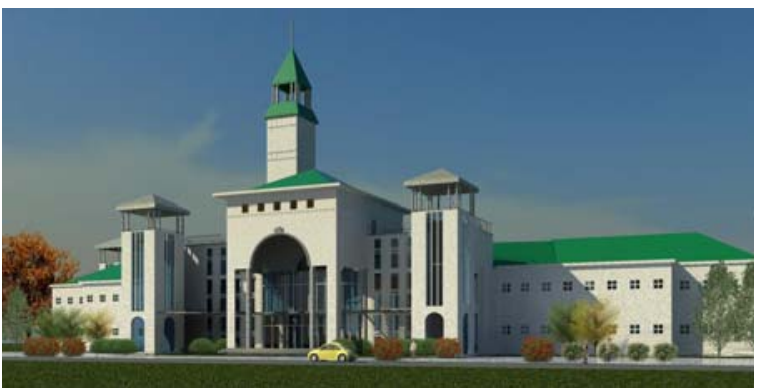

2014.6

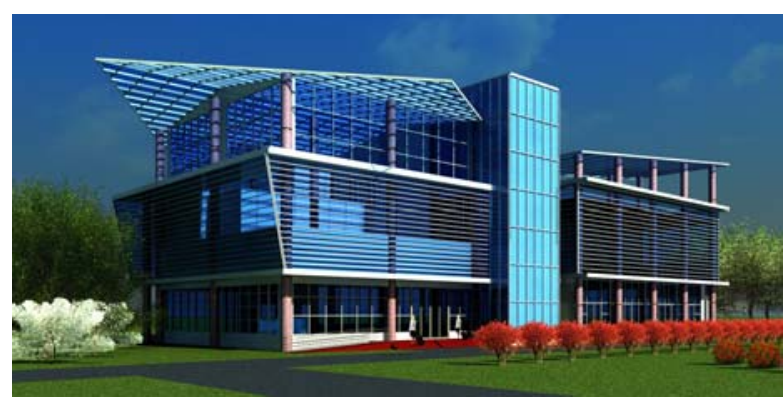

2014.8

FIGURE I STUDENTS' EXERCISES OF BIM IN DEFFERENT PERIOD

From Figure I, the progress are rapidly in short time by taking MOOM course. It means the MOOC style are useful for BIM education.

By taking MOOC of BIM, the approach has changed from teacher-centered to learner-centered, in this way, the students are more likely to work hard for their acquirement, and they can arrange the study time by themselves. This is why the MOOC style getting more and more accepted.

\section{CASE STUDY AND REAL PROJECT}

For BIM study, case study and real project are very important. When the student get to a higher level, they are eager to take part in the real project. In2014, five of these students make a group and began to do real project, they fulfilled a construction model and a structure model of a museum named Wuqi in XIAN totally by themselves, they also gave a collision test report by collision analysis of the construction model and the structure model.

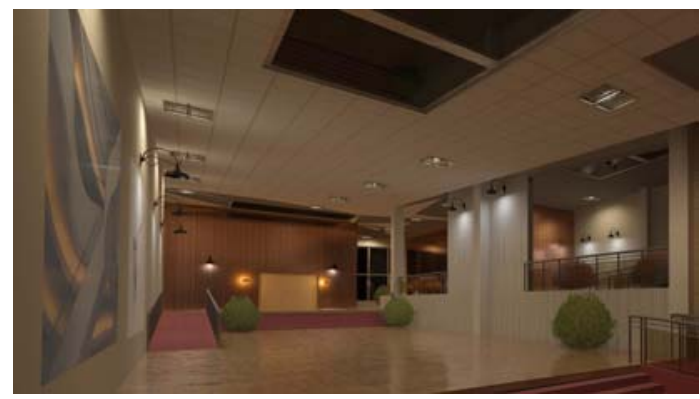

(a) Inside Model 


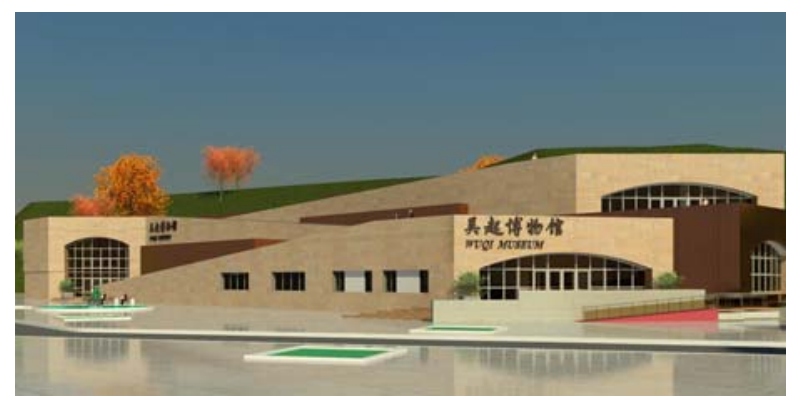

(b) Construction model(2014.11)

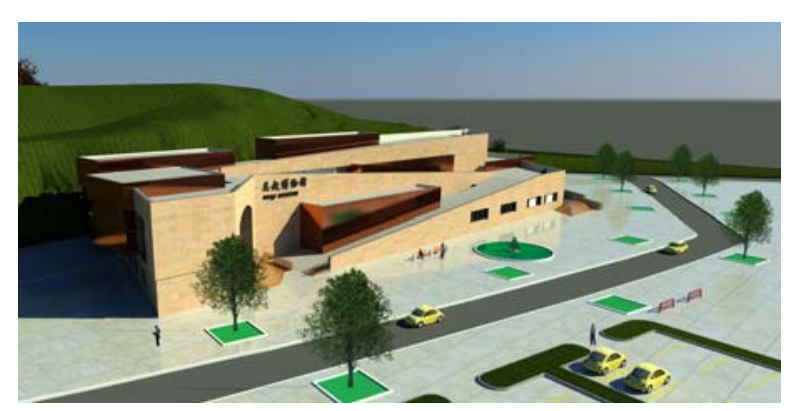

(b)Construction model

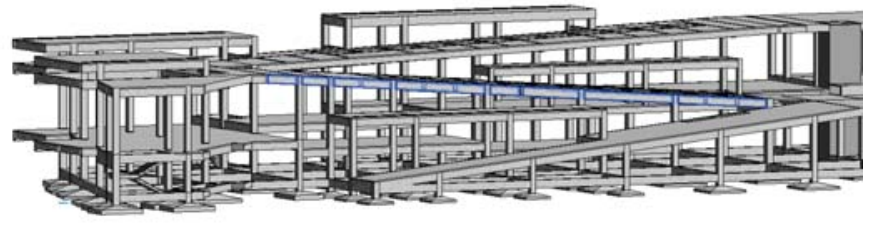

(c)Structure model

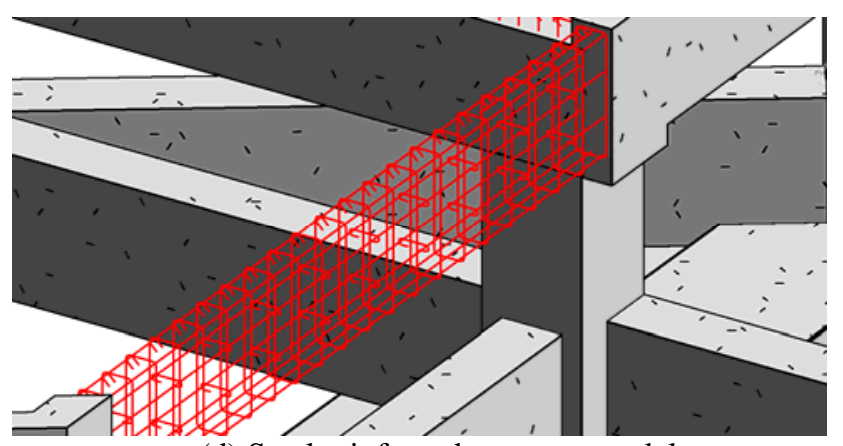

(d) Steel reinforced concrete model
TABLE I. COLLISION TEST REPORT

\begin{tabular}{|l|c|c|}
\hline \multicolumn{1}{|c|}{$\begin{array}{c}\text { Construction } \\
\text { model }\end{array}$} & Structural model & $\begin{array}{c}\text { Steel reinforced } \\
\text { concrete }\end{array}$ \\
\hline & N.O.12 & N.O.8 \\
KL3 300*750 & KL10 300*700 \\
\hline LC5 & L2 & \\
\hline LC2 & KL1 & \\
\hline N.O.13 & N.O. 07 KZ1 & \\
\hline
\end{tabular}

Figure II shows the construction model, structural model and steel reinforced concrete model. These models are set by the undergraduate students themselves in 2 months.

For these students, through the MOOC course of BIM, they master a higher level skill and have the abilities to take part in the real project.

From 2013, more than 100 students took the MOOC course of BIM in HIT of their own free will, although some of them quit, most of them finish the course. Fifteen of these student took part in the national university student advanced drawing contest and win the first prize. Five of these students make a team and get the supported of National training programs.

MOOC could be used in variety style by the understanding of teachers and students. MOOC play an important role in university education.

\section{ACKNOWLEDGMENT}

This research was financially supported by the Higher Education and Teaching Reform of Heilongjiang Province (Grant No. JG2014010691), the National Training Programs of Innovation and Entrepreneurship for Undergraduates (Grant No. 2014S34147) and the 2014 Youth Special of Teaching Research Projects of Harbin Institute of Technology (Grant No. HIT20140105).

\section{REFERENCES}

[1] Aguaded-Gomez, J. Ignacio. The MOOC Revolution: A new form of education from the technological paradigm?: COMUNICAR[J]. 2013,(41): 7 8

[2] HARDEN N. The End of the UniversityQas We Know It[J].The American Interest, 2013(3):54-62.

[3] Lin, YC. Use of BIM approach to enhance construction interface management: a case study. JOURNAL OF CIVIL ENGINEERING AND MANAGEMENT.2015,21(2):201-217

FIGURE II BIM models of Wuqi Museum 